\title{
Hydromechanical behavior of a quasi-saturated compacted soils on drying-wetting paths-experimental and numerical approaches
}

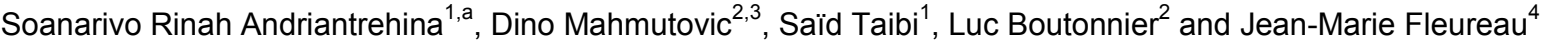 \\ $\square$

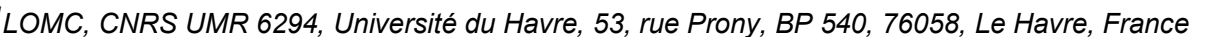 \\ प्र

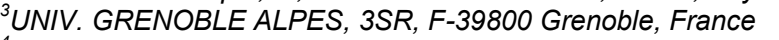

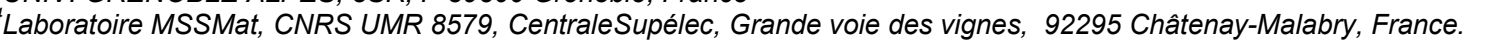 \\ $\square$
}

\begin{abstract}
This paper presents an experimental and numerical investigation funded by the French National Project "Terredurable", which is devoted to the study of soils in quasi-saturated state. The experimental study is focused on the behavior of compacted soils on drying-wetting paths and the macroscopic effect of the drying path on shrinkage and cracking. Furthermore, a protocol for image analysis of crack in drying tests was developed. Two approaches are used for the measurement of surface strains and identification of the ultimate stress before the formation of the first crack, using VIC-2D software, and for the monitoring of crack evolution, using ImageJ software. The aim of the numerical approach is to reproduce the drying experiments with a finite difference code (FLAC 3D), in order to understand the stress conditions that can explain crack initiation, without modeling the crack formation itself.
\end{abstract}

\section{Introduction}

Compacted soils used in geotechnical engineering are the result of the densification of soil by application of mechanical energy. They are often in an unsaturated state and subjected to suction. In the laboratory, the characterization of compacted soil is generally carried out by standardized Proctor tests $[1,2,3]$. In the literature, many studies are devoted to the behavior of compacted soils on drying wetting paths $[4,5]$ and the induced cracking desiccation $[6,7]$.

This paper presents an experimental and numerical investigation carried out on a compacted marl on dryingwetting paths. The experimental study is focused on the behavior of compacted soils on drying-wetting paths and the macroscopic effect of drying on shrinkage and cracking. The aim of the numerical approach is to reproduce the drying experiments with a finite difference code (FLAC 3D). The originality of this paper is to treat the problem of desiccation cracking of compacted soils related to the suction which is responsible for the appearance of the first cracks

\section{Material}

The study was performed on a high-plasticity marl whose properties are summarized in Table 1. The standard Proctor optimum, water content and maximum density are consistent with the values given by the correlations of [5] (Fleureau et al. 2002), and [8] (Biarez and Favre
1975), based on the liquid limit of the material, as shown in Table 1. According to the USCS classification [9], the marl is a highly plastic clay $(\mathrm{CH})$ with a percentage of $\mathrm{CaCO}_{3}$ ranging from 30 to $40 \%$. In the French road classification GTR 92 [10], the marl is classified as A4, and in the American Association of State Highway and Transport Officials (AASHTO) classification [11], it is classified as A7.

Table 1. Properties of the marl.

\begin{tabular}{|c|c|}
\hline $\begin{array}{c}\text { Grain size distribution } \\
<80 \mu \mathrm{m}(\%) \\
<2 \mu \mathrm{m}(\%)\end{array}$ & 94 \\
$\mathrm{Cu}$ & 36 \\
\hline $\mathrm{Cc}$ & 6.25 \\
\hline $\mathrm{w}_{\mathrm{L}}(\%)$ & 80.93 \\
\hline $\mathrm{w}_{\mathrm{SPO}}(\%)$ & 24.5 \\
Measured & 31 \\
Fleureau et al. 2002 & 32 \\
Biarez and Favre 1975 & \\
\hline$\gamma_{\mathrm{d}} / \gamma_{\mathrm{w}}$ at SPO & 1.50 \\
Measured & 1.37 \\
Fleureau et al. 2002 & 1.35 \\
Biarez and Favre 1975 & $30-40$ \\
\hline $\mathrm{CaCO}_{3}$ content $(\%)$ &
\end{tabular}

\footnotetext{
a Corresponding author: andrians@univ-lehavre.fr
} 


\section{Methods}

\subsection{Drying-wetting paths}

Several methods were used to control suction in the samples [5]. For suction lower than $20 \mathrm{kPa}$, the samples were placed on tensiometric plates, and a negative pressure was applied to water, the air pressure being atmospheric. For suctions ranging from 50 to $8000 \mathrm{kPa}$, the osmotic technique was used. In this technique, the sample is in contact with a solution of organic macromolecules of polyethylene glycol PEG (molar weights of 20000 and 6000 for negative pressures ranging from 50 to $1500 \mathrm{kPa}$, and $3 \mathrm{MPa}$ to $8 \mathrm{MPa}$, respectively) through a semi-permeable membrane which only allows water molecules to pass. For higher suctions, saturated salt solutions were used, the transfer of water then occurring in vapor phase. Samples were placed in desiccators in which the relative humidity of the atmosphere was controlled by several salt solutions.

Once the equilibrium was reached, the final properties of the samples were measured. The samples were weighed, and then immersed in non-wetting oil (commercial kerdane). Their external volume was derived from the difference between their weight after wetting and their apparent weight while immersed in kerdane. Finally, their dry weight was measured after evaporation of both water and oil in an oven at $105^{\circ} \mathrm{C}$ for $24 \mathrm{~h}$.

\subsection{Free drying tests with image analysis}

The drying tests with image analysis were carried out on compacted soil samples with a water content equal to $27.5 \%\left(\mathrm{w}_{\mathrm{SPO}}+3 \%\right)$. The sample $(2 \mathrm{~cm}$ thick $)$ was compacted in a CBR mold, then put on a precision balance. Drying tests were performed under controlled relative humidity $(30 \% \pm 5 \%)$ and temperature $\left(22^{\circ} \mathrm{C} \pm\right.$ $1{ }^{\circ} \mathrm{C}$ ) conditions. The experimental device (Figure 1) consists of a sample support placed on a precision balance and a camera taking photos at regular time intervals during the free drying test $[12,13]$. The water content measured via the precision balance is an average value in the sample over the total dry mass.

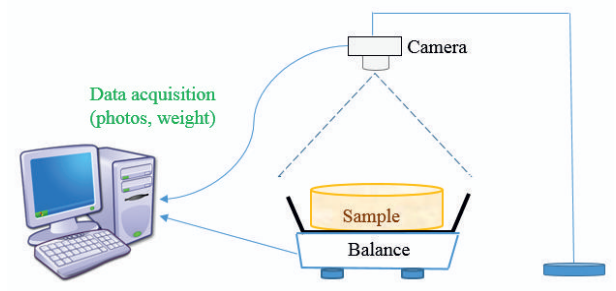

Figure 1. Schematic of experimental setup.

Two approaches were used for the measurements [13, 14]:

- Before failure (cracking), measurement of surface strains and identification of the ultimate stress before the formation of the first crack, using VIC-2D software for digital image correlation. At regular time intervals during the free drying tests, photos of the soil surface are taken and analyzed to provide two-dimensional strain maps of the complete planar specimen.
- Study of crack evolution, geometrical measurements and percentage of cracks as a function of water content. Crack evolution is analyzed using ImageJ software. The technique consists in identifying the cracks on a grey scale image using a threshold. The crack ratio, called CR, is defined as the ratio between the total area of cracks and the area of the soil sample:

$$
\mathrm{CR}=\frac{\text { Area of cracks }}{\text { Area of the sample }}
$$

Suction is derived from water content on drying path, at the times corresponding to crack formation.

\subsection{Numerical approach of the free drying test}

The aim of the numerical approach is to reproduce the drying experiments with the finite difference code FLAC 3D (Fast Lagrangian Analysis of Continua in 3D). The objective is to understand the stress conditions that can explain crack initiation, without modeling the crack itself.

\section{Calculation assumptions}

Geometry

The geometry of the numerical model is that of the experimental sample: it is a circular disk, $2 \mathrm{~cm}$ thick and $15 \mathrm{~cm}$ in diameter. However, square mesh was preferred to minimize its influence on the results. Therefore, the shape is approached through a fine mesh using 30000 elements (Figure 2).
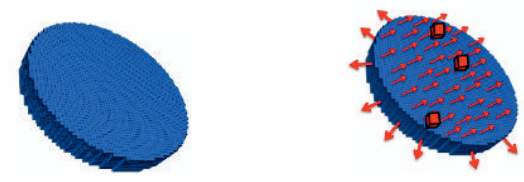

Figure 2. Overview of the sample modeled with square mesh (30000 elements) - Initial state corresponds to the sample.

\section{Initial state}

The model reproduces the initial conditions of the experimental test (compacted sample in Proctor test, drying test). The preconsolidation stress of $200 \mathrm{kPa}$ is deduced from an oedometer test carried out on a sample identical to that of the drying test. The initial suction value of $60 \mathrm{kPa}$ is also derived from the experimental measurements.

\section{Boundary conditions}

Two boundary conditions are defined:

- No movement of the sample base: the translation along the $\mathrm{z}$ axis is blocked, those in the other directions are permitted. The support of the sample for the experimental test validates this approach.

- A flow boundary condition is applied at the ends of the model in contact with air. In fact, water in contact with the atmospheric pressure progressively evaporates and creates a flow transfer. We tried to reproduce this phenomenon by imposing a transfer of water equivalent to that measured in the experimental test. Table 2 summarizes the water flow recorded during the drying test for different time periods. Numerical modeling aims to reproduce this phenomenon. 
Table 2. Calculation of water flow transfers imposed on the numerical model boundary conditions.

\begin{tabular}{|c|c|c|c|c|c|c|c|c|}
\hline Phase & Periods & $\begin{array}{c}\text { Durations } \\
(\mathrm{s})\end{array}$ & $\begin{array}{c}\text { Water loss } \\
(\mathrm{g})\end{array}$ & $\begin{array}{c}\text { Lateral area } \\
\left(\mathrm{m}^{2}\right)\end{array}$ & $\begin{array}{c}\text { Disk area } \\
\left(\mathrm{m}^{2}\right)\end{array}$ & $\begin{array}{c}\text { Total area } \\
\left(\mathrm{m}^{2}\right)\end{array}$ & $\begin{array}{c}\text { Flow } \\
(\mathrm{l} / \mathrm{s})\end{array}$ & $\begin{array}{c}\text { Flow } \\
\left(1 / \mathrm{s} \cdot \mathrm{m}^{2}\right)\end{array}$ \\
\hline 1 & $\mathrm{t} 0-\mathrm{t} 1$ & 2700 & $1,54 \mathrm{E}+00$ & $9,43 \mathrm{E}-03$ & $1,77 \mathrm{E}-02$ & $2,71 \mathrm{E}-02$ & $7,12 \mathrm{E}-07$ & $2,63 \mathrm{E}-05$ \\
\hline 2 & $\mathrm{t} 1-\mathrm{t} 2$ & 900 & $3,86 \mathrm{E}-01$ & $9,43 \mathrm{E}-03$ & $1,77 \mathrm{E}-02$ & $2,71 \mathrm{E}-02$ & $5,36 \mathrm{E}-07$ & $1,98 \mathrm{E}-05$ \\
\hline 3 & $\mathrm{t} 2-\mathrm{t} 3$ & 20700 & $1,07 \mathrm{E}+01$ & $9,43 \mathrm{E}-03$ & $1,77 \mathrm{E}-02$ & $2,71 \mathrm{E}-02$ & $6,44 \mathrm{E}-07$ & $2,38 \mathrm{E}-05$ \\
\hline 4 & $\mathrm{t} 4-\mathrm{t} 5$ & 78300 & $3,77 \mathrm{E}+01$ & $9,43 \mathrm{E}-03$ & $1,77 \mathrm{E}-02$ & $2,71 \mathrm{E}-02$ & $6,02 \mathrm{E}-07$ & $2,22 \mathrm{E}-05$ \\
\hline
\end{tabular}

\section{Mechanical and hydraulic parameters}

\section{Mechanical constitutive law and associated parameters}

The constitutive law plays an important role in predicting stresses in this simulation. However, it has no effect on volumetric strains. Indeed, drying is studied for suctions lower than the air entry pressure (desaturation of the sample). In this domain volumetric strains correspond to normal shrinkage, i.e. volume decrease caused by evaporation of water. Beyond that domain, the model is no longer valid.

Two different constitutive laws were tested: an elastoplastic law (modified Cam-Clay) and a perfect plastic law (Mohr Coulomb). The first one correctly reproduces the overall behavior but it is unstable in areas where strain softening develops. Under these conditions, Mohr Coulomb helps to treat the areas of heterogeneities where cracks can potentially develop. The mechanical parameters of these two laws were derived from the experimental tests (triaxial and oedometer tests).

Table 3. Mechanical parameters of the used constitutive laws

\begin{tabular}{|c|c|c|c|}
\hline \multicolumn{2}{|c|}{ Cam-Clay parameters } & \multicolumn{2}{c|}{ Mohr Coulomb parameters } \\
\hline$\lambda$ & 0,3 & $\mathrm{~K}$ & $1517 \mathrm{kPa}$ \\
\hline$\kappa$ & 0,04 & $\mathrm{G}$ & $910 \mathrm{kPa}$ \\
\hline $\mathrm{P}_{0}^{\prime}$ & $120 \mathrm{kPa}$ & $\mathrm{Phi}$ & $13^{\circ}$ \\
\hline $\mathrm{M}$ & 0,7 & $\mathrm{c}$ & $40 \mathrm{kPa}$ \\
\hline $\mathrm{vp} 1$ & 2,8 & & \\
\hline
\end{tabular}

\section{Flow law, hydraulic parameters}

The used numerical model is a coupled model that considers the flows. Darcy law was used, with a measured permeability of $10^{-11} \mathrm{~m} / \mathrm{s}$. The sample is considered as quasi-saturated. Indeed, air is present in the sample in the form of occluded air bubbles in water, forming a homogeneous and compressible pore fluid. The behavior of this fluid is considered in the modeling through a saturation equal to 1 and a compressibility factor taken equal to $6.10^{-5} \mathrm{kPa}^{-1}$ (based on feedback for this soil type $[15,16,17])$.

\section{Results}

\subsection{Drying-wetting paths}

Figures 3 and 4 show the drying-wetting paths. Graphs A and $\mathrm{C}$ illustrate the void ratio and the degree of saturation as a function of water content. Graphs B, D, and E show void ratio, degree of saturation, and water content as a function of suction.

\section{Slurry samples}

Graph A shows the shrinkage curve. On drying path, the soil follows the saturation line, with the equation:

$$
e=w \cdot\left(\gamma_{s} / \gamma_{w}\right)
$$

down to the shrinkage limit water content, after which the void ratio becomes constant. The shrinkage limit $\mathrm{w}_{\mathrm{SL}}=$ $20 \%$ is positioned at the intersection of the saturation line with the asymptote of the curve for $\mathrm{w}=0$.

Graph B shows the compressibility of the soil (void ratio as a function of suction). This graph present a domain characterized by a significant decrease in void ratio, followed by a stabilization of the void ratio. The shrinkage suction $\mathrm{s}_{\mathrm{SL}}\left(\mathrm{s}_{\mathrm{SL}}=3 * 10^{4} \mathrm{kPa}\right)$ is the suction of the point at the beginning of this stabilization, related to the shrinkage limit water content of the soil. NC and OC correlation curves [8], derived from the $\mathrm{w}_{\mathrm{L}}$ of the material, are shown in this graph to compare with the position of the wetting and drying paths of the material. The drying path follows the Cc correlation line and the wetting path follows the Cs correlation line. Graph C shows that the material was initially saturated. The degree of saturation decreases slowly up to the air entry point, then decreases sharply with the water content. In graph $\mathrm{D}$, the soil continues to be quasi-saturated up to the desaturation suction $\mathrm{s}_{\mathrm{d}}=1.5 \mathrm{MPa}$. This domain corresponds to an irreversible behavior for the drying and wetting paths of the material. Then, the degree of saturation decreases quickly. This rapid decrease in the degree of saturation results in the fall of the water content (Graph E). Graph E $[\log$ s; w] corresponds to the usual retention curves graph, in which the axes are reversed to highlight the correspondence between the changes in void ratio, degree of saturation, water content and suction. For suctions lower than the desaturation suction, variations in water content and void ratio are related, while for higher suctions, the water content varies with the degree of saturation. In the domain of high suctions where the water content and the void ratio vary little, the hysteresis between drying and wetting paths is negligible. The domain where the increase in water content and degree of saturation is more important, and where the variation of the void ratio is not significant, is an intermediate phase of resaturation. In this domain, the hysteresis between the drying and wetting paths appears in the graphs D and E. This hysteresis is mainly the result of "ink-bottle" effect. In the domain of low suctions, the material is quasisaturated even if the water content and void ratio continue to grow. The maximum degree of saturation is less than 1. Thus, the behavior is not reversible in this domain. 

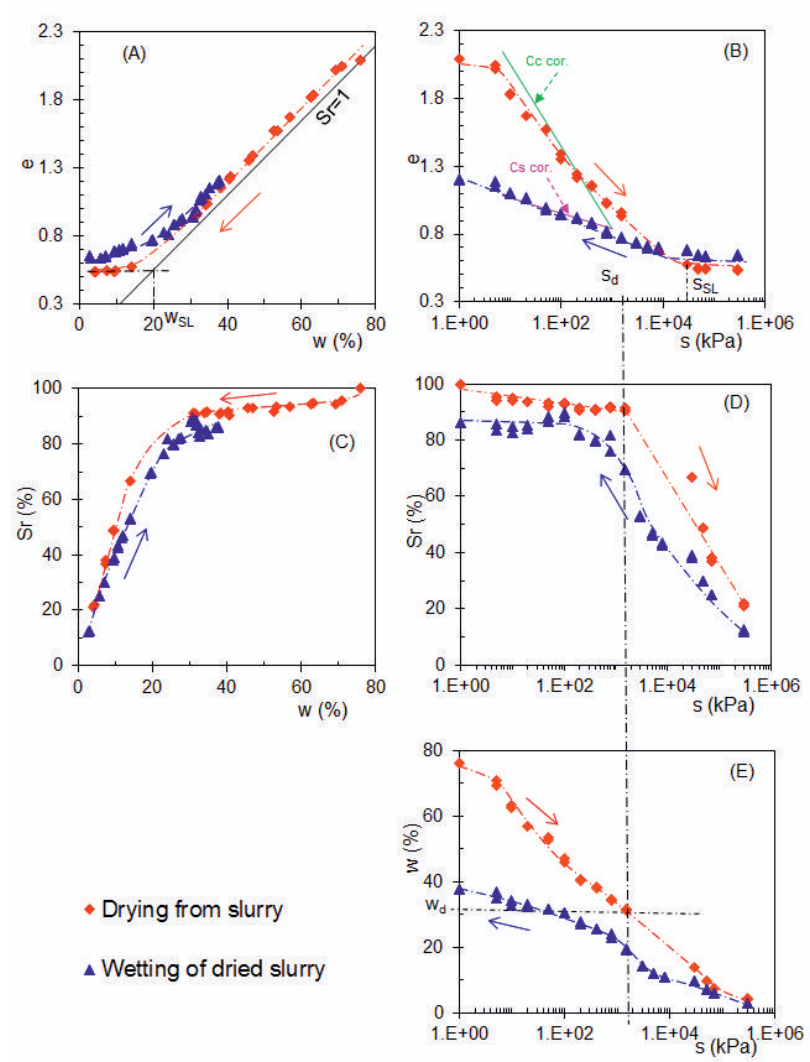

Figure 3. Drying-wetting paths of samples of slurry.

\section{Compacted samples}

At the SPO, the material water content is $24.5 \%$ and the void ratio is 0.77 . So, graphs $\mathrm{B}$ and $\mathrm{E}$ give a value of the suction $\mathrm{S}_{\mathrm{SPO}}$ of approximately $800 \mathrm{kPa}$.
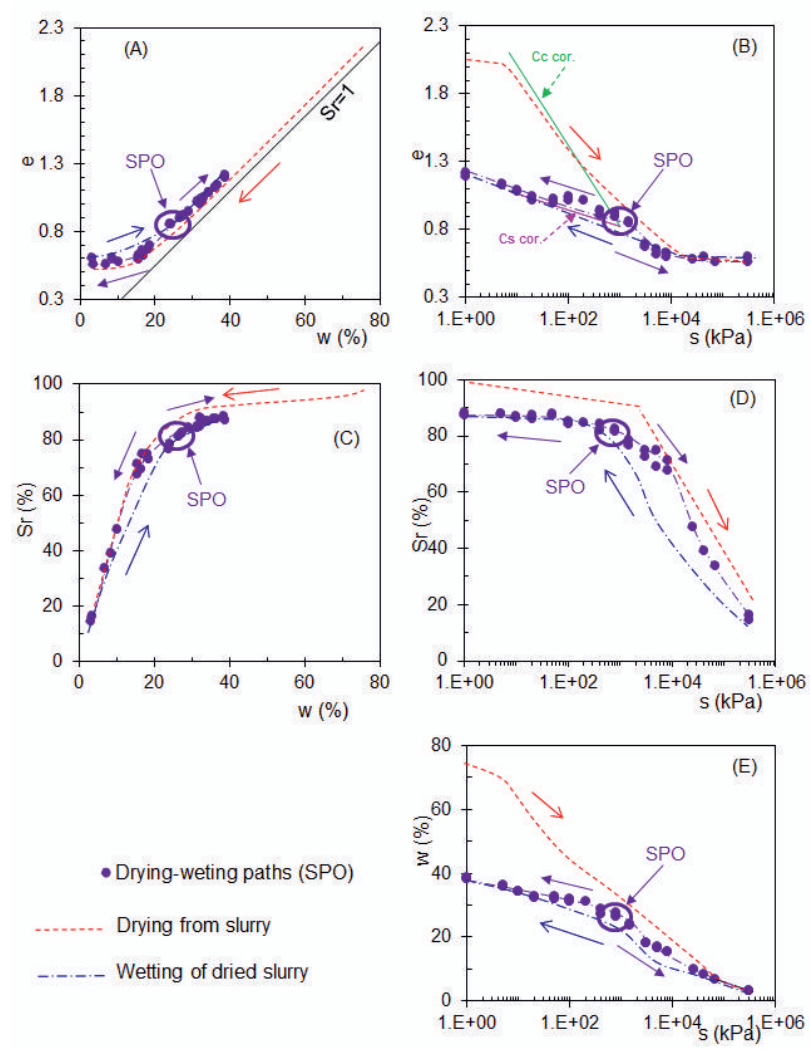

Figure 4. Drying-wetting paths of compacted samples.
As the $\mathrm{s}_{\mathrm{SPO}}$ value is smaller than the value of the shrinkage limit suction and the void ratio $\mathrm{e}_{\mathrm{SPO}}$ is larger than the shrinkage limit void ratio of the samples of slurry, the drying path rejoins the Cc line, down to the shrinkage limit void ratio of the paste, then follows the same path. Wetting path follows the Cs correlation line. The drying and wetting paths are very close to the wetting path of dry slurry samples.

\subsection{Free drying tests with image analysis}

The free drying test on the compacted marl (Figure 5a) was followed up to stability of the water content (residual water content). The formation of cracks was observed, with a more or less random distribution. The photo below (Figure 5a) shows the difference between the initial state (left) and final state (right) of the material.
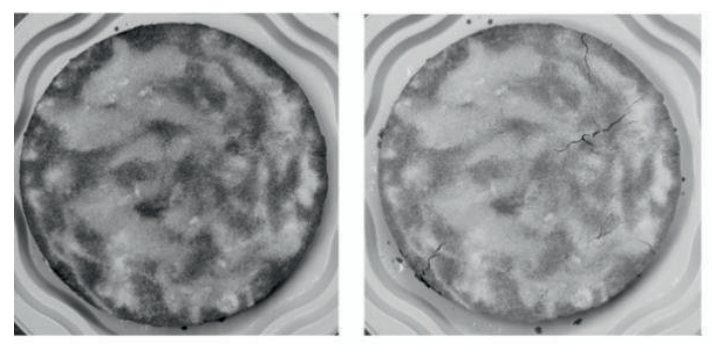

Figure 5a). Free drying of the compacted marl.

During the first 40 hours, the rate of evaporation of water is constant $(0.037 \mathrm{~g} / \mathrm{min})$ and the water content decreases down to $12 \%$, called the critical water content. After 100 hours, evaporation stops and the residual water content is equal to $5.7 \%$, as shown in Figure $5 \mathrm{~b}$. The first crack appears after $45 \mathrm{~min}$ at an average water content of $27.1 \%$.

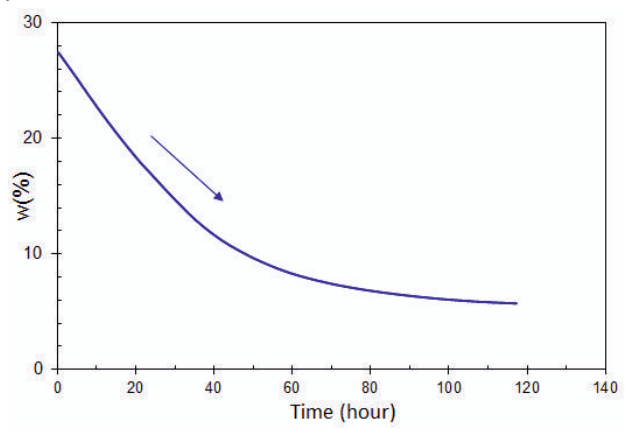

Figure 5b). Variation of water content function of time.

Analysis of the strain field on the sample surface deduced from image correlation (Figure 6) shows a first localization of large strains at certain locations, which then results in the formation of cracks in the first hours of desiccation. This network of cracks spreads and stabilizes when the water content is close to the material shrinkage limit water content $\left(\mathrm{w}_{\mathrm{SL}}=16 \%\right)$. This value is confirmed by the drying-wetting test shown above, interpreted in terms of volumetric strains (Figure 6). According to this test, the volume strain increases linearly (contractancy) when the water content decreases, up to an $\varepsilon_{\mathrm{v}}$ value of about $15 \%$, before reaching a constant value. 


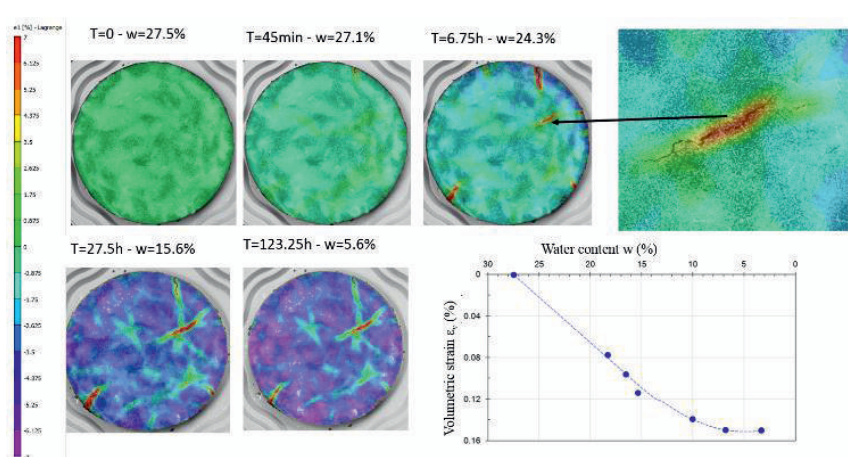

Figure 6. Evolution of the strain field versus time - evolution of the volumetric strain as a function of the water content.

Figure 7 presents the variation of the crack ratio derived from Image J. Starting from a water content of about $27.5 \%$, the sample begins to dry without cracking. The first crack occurs at an average water content of about $27.1 \%$. As the average water content decreases, there is a sudden increase in crack ratio when water content is about $21.7 \%$, and then a trend toward stabilization is observed during the rest of drying.

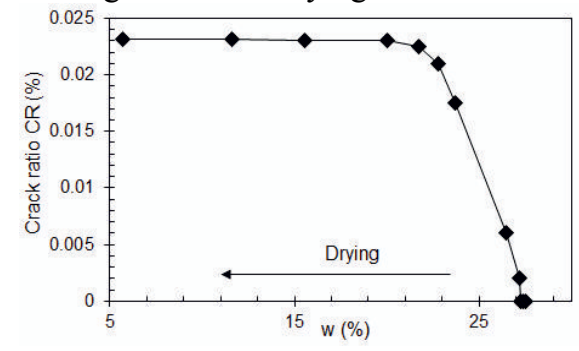

Figure 7. Crack ratio.

Figure 8 shows the drying-wetting paths of compacted soil presented above, where the initial state of the sample in the free drying test is indicated, as well as the formation of the first crack and the point where the cracks stabilize. The first crack appears at a suction around 400 $\mathrm{kPa}$ and cracking stabilizes (ie when the cracking no longer changes, while drying continues) around $4 \mathrm{MPa}$.

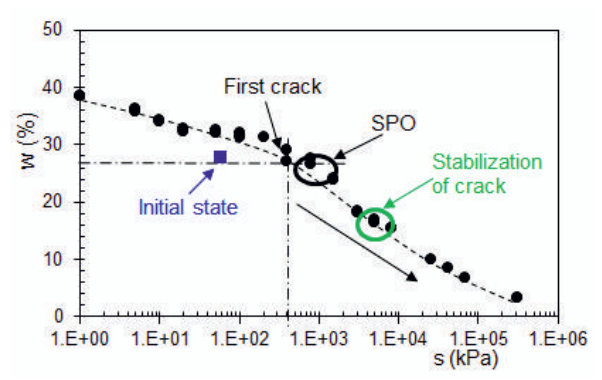

Figure 8. Suction values deduced from drying path.

\subsection{Numerical approach of the free drying test}

Several phenomena were followed by: (1) the volumetric deformation of the entire sample due to evaporation of water at the borders of the model - (2) changes in pore pressure within the sample - (3) areas for the development of cracks.

\section{Volumetric strains}

The change in total volume was followed during numerical simulation (Figure 9). The soil sample progressively shrinks in time due to water transfer; the decrease in volume corresponds to the volume of water evaporated. The simulations were stopped at a water content close to that of air entry $(16 \%)$. It was also considered that normal shrinkage continues to the end of the total deformation of the sample, without consideration of the residual deformation. This assumption is acceptable because cracks appear and develop mainly in the normal shrinkage area $[18,19,20]$.

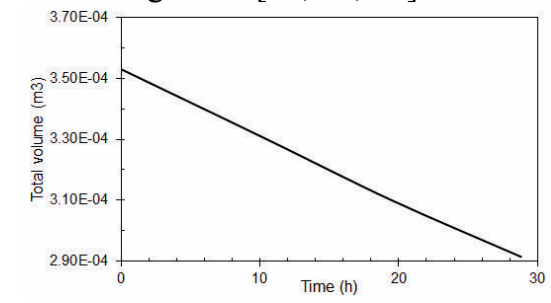

Figure 9. Evolution of the total volume by numerical approach.

\section{Suction prediction}

The flow imposed at the ends of the model avoids taking water into account. The degree of saturation of the sample always remains constant and equal to 1 . The effect of that is a decrease in volume and an increase in suction of the sample. FLAC allows to visualize the evolution of suction in the sample over time (Figure 10). The final suction was not measured experimentally in the sample. However, the values obtained, though qualitative, are consistent with the soil retention curve and the phenomenon of contractancy.

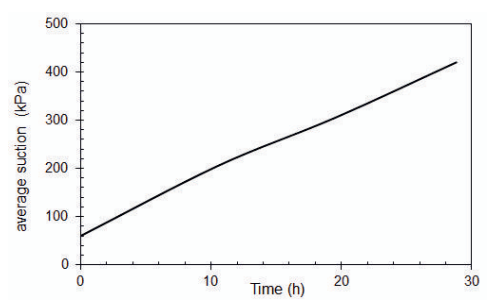

Figure 10. Evolution of the suction by numerical approach.

\section{Prediction of areas that can be potentially cracked}

The occurrence of cracks is conditioned by the presence of heterogeneities in the sample (carbonated elements, mainly shells, dispersed in the skeleton.

The aim of modeling is to highlight the specific and local behavior of the soil around areas of weakness or high resistance. So, three stiff areas were introduced in the numerical model to simulate the cracks observed in the experimental test results (Figure 11). These areas are intended to model the presence of discontinuities so as to see if the obtained stress state is the more conducive to surface cracking. Drying is free and the sample does not undergo the effect of any load. Its total average stress should be zero. Now it can be seen that areas of high tensions in total stresses appear in the right area of the stiff areas. These areas may lead to the formation of cracks and their development. This observation can also be made with respect to shear forces, in which one can see the influence of the stiff zones. 


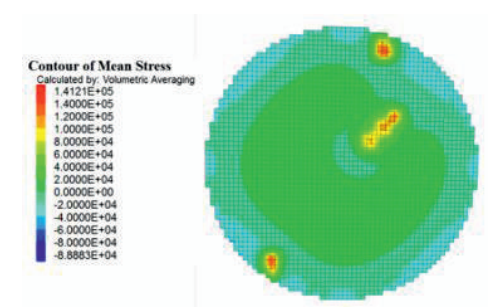

Figure 11. Highlighting areas of high tensions.
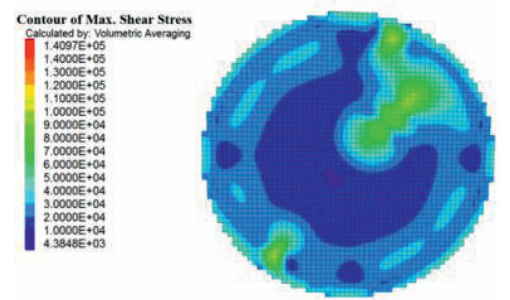

Figure 12. Visualization of shear stress to the sample surface Highlighting high shear zones around the hard points.

\section{Conclusion}

Experimental and numerical approaches are presented in this paper concerning the behavior and cracking of a remolded compacted high plasticity marl on dryingwetting paths. The results show the interest of a global representation of the state of materials in drying-wetting paths, allowing to follow the evolution of soil saturation and link shrinkage characteristics and desaturation to drying properties. Free drying tests highlighted the initial conditions of crack formation (water content, suction ...) which occurs in the quasi-saturated domain of the material. The numerical approach allows to model the phenomena and proves that cracks are initiated close to saturation and for suctions lower than the desaturation suction.

\section{Acknowledgment}

The authors acknowledge the French ANR project TerreDurable (ANR 2011 VILD 00401 convention, programme Bâtiments et villes durables).

\section{References}

1. $\square$ AFNOR 1999 - NF P 94-093. Détermination des références de compactage d'un matériau, Essai Proctor normal - Essai Proctor modifié.

2. $\square$ ASTM D 698-12. Standard Test Methods for Laboratory Compaction Characteristics of Soil Using Standard Effort $\left(600 \mathrm{kN}-\mathrm{m} / \mathrm{m}^{3}\right)$.

3. $\square$ ASTM D 1557-12. Standard Test Methods for Laboratory Compaction Characteristics of Soil Using Modified Effort $\left(2,700 \mathrm{kN}-\mathrm{m} / \mathrm{m}^{3}\right)$.

4. $\square$ S. Kheirbek-Saoud, "Comportement mécanique de la couche de fondation d'une voie ferrée", Thèse de doctorat, Ecole centrale Paris (1994).

5. J-M. Fleureau, J. C. Verbrugge, P.G. Huergo, A. Gomes Correia, S. Kheirbek-Saoud, "Aspects of the behaviour of compacted clayey soils on drying and wetting paths", Can. Geotech. J., 39, pp. 1341-1357, (2002).
6. $\square$ C.J. Miller, H. Mi, N. Yeiller, "Experimental analysis of desiccation crack - Propagation in clay liners", JAWRA 34 (3), pp. 677-686.

7. R. Auvray, S. Rosin-Paumier, A. Abdallah, F. Masrouri, "Etude de la fissuration due à la dessiccation des sols gonflants", 21éme Congrès Français de Mécanique, Bordeaux, (2013).

8. $\square$ J. Biarez and J. L. Favre J L. Parameters filing and statistical analysis of dada in soil mechanics. Proceedings of the 2nd Int. Conf. on Application of Statistics and Probabilities in Soil Mechanics, Aachen, Vol. 2, pp. 249-264 (1975).

9. $\square$ ASTM D 2487- 06. Standard Practice for Classification of Soils for Engineering Purposes (Unified Soil Classification System).

10. AFNOR 1992 - NF P11-300. Exécution des terrassements - Classification des matériaux utilisables dans la construction des remblais et des couches de forme d'infrastructures routières.

11. $\square$ ASTM D 3282-09. Standard Practice for Classification of Soils and Soil-Aggregate Mixtures for Highway Construction Purposes.

12. X. Wei. Etude micro-macro de la fissuration des argiles soumises à la dessiccation, Thèse de doctorat, Ecole Centrale Paris (2014).

13. J. Eid, S. Taibi, J-M. Fleureau, M. Hattab, Drying, cracks and shrinkage evolution of a natural silt intended for a new earth building material. Impact of reinforcement, J. Con. Build. Mat. 86, 120-132 (2015).

14. R. Andrianatrehina, D. Mahmutovic, L. Boutonnier, S. Taibi, S. J-M. Fleureau, J-J. Fry, J. Monnet. Observation of craking evolution during free dessication - experimental and numerical approaches. Symposium international SEC (2015). Marne-la-vallée.

15. L. Boutonnier. Comportement hydromécanique des sols fins proches de la saturation. Cas des ouvrages en terre : coefficient $\mathrm{B}$, déformations instantanées et différées, retrait / gonflement. Thèse INPG Grenoble (2007).

16. L. Boutonnier. Mechanics of unsaturated geomaterials, Chap.14: Coefficient B, Consolidation and swelling in Fine Soils near saturation in Engineering Practice. Ed. L. Laloui, J. Wiley. (2010).

17. L. Boutonnier, G. Mahmutovic, J-J. Fry. Génération de pression interstitielle dans les fondations argileuses des barrages en remblai. Colloque CFBR (2015).

18. H. Péron, L. Laloui, T. Hueckel, L. Hu. Experimental study of desiccation of soil. Proceedings of the Fourth International Conference on Unsaturated Soils, (Vol 1, pp. 1073-1084). Reston, VA: American Society of Civil Engineers. (2006).

19. H. Péron, T. Herchel, L. Laloui, L. Hu. Fundamentals of desiccation cracking of fine-grained soils: experimental characterization and mechanisms identification. Can. Geotech. J. 46, 1177-1201. (2009).

20. H. Nahlawi, J.K. Kodikara. Laboratory experiments on desiccation cracking of thin soil layers. Geotech. Geol. Eng. 24, 1641-1664. (2006). 